\title{
TRISOMY 21, A CONSEQUENCE OF ADVANCED MATERNAL AGE
}

Author: 1. Osati Otieno Elisha, MD (Intern doctor at Temeke Municipal Hospital Dar es Salaam, Tanzania).

DMSJ 2012; 19: 5-6 http://dx.doi.org/10.4314/dmsj.v19i1.1

\begin{abstract}
K.M, a 1 year and 9 month old male child from Mwanza was referred from Bugando Hospital to Muhimbili National hospital for further investigations and management. He presented with gradual onset of dry recurrent cough and difficulty in breathing for 20 months and low grade recurrent fever for 9 months. His mother was 43 years and father 45 years old.

On examination he was alert, febrile $\left(38.5^{\circ} \mathrm{C}\right)$, acyanotic, with up-slanting eyes, low set ears, flat nose-bridge, small chin, short neck, pigeon chest and webbed toes. He was malnourished with delayed developmental milestones. A pansystolic murmur was auscultated at the lower left sternal edge; and he had impaired speech, reduced muscle bulk and muscle tone with muscle power of grade 3 .
\end{abstract}

\section{Correspondent:}

Dr. Osati Otieno Elisha, Mobile \#: +255 714553 237/ +255 786902 753,

Mail address: P.O.BOX 100007 Dar es Salaam, Tanzania, Email: elishaosati@yahoo.com 


\section{Introduction}

In 1866, Down described clinical characteristics of the syndrome that now bears his name $e^{1,2}$. Lejerune and Jacobs et al independently determined that Down syndrome is caused by trisomy ${ }^{2}$ 21. The extra chromosome 21 affects almost all organ systems and results in a wide spectrum of phenotype consequences such as mental retardation, characteristic facial features, hand anomalies and congenital heart disease. It can be diagnosed prenatally through amniocentesis, percutaneous, and umbilical blood sampling, chorionic villus sampling and extraction of total cells from maternal circulation ${ }^{3}$. Parents of a child with Down syndrome are often concerned about developmental delay, respiratory infections, delay in cognitive ability, poor motor and language development and social competence, fainting episodes, difficulty in breathing secondary to a heart lesion, hypotonia which improves with age, sleep apnea, genuine warmth, cheerfulness, gentleness, patience and tolerance ${ }^{4}$. Advanced maternal age remains the only well documented risk factor for maternal meiotic non-disjunction ${ }^{5}$, though advanced paternal age is also questioned $^{6}$.

\section{CASE PRESENTATION}

K.M., a 1 year and 9 month old male from Mkuyuni, Mwanza was referred from Bugando Hospital to Muhimbili National Hospital for further investigations and management. He came with the chief complaints of cough and difficulty in breathing for 20 months and recurrent fever for 9 months.

He had experienced cough since day 3 of life. The cough was dry with no specific periodicity and had no relation to his posture. Three weeks later he developed difficulty in breathing and easy fatigability observed during breastfeeding. The first episode of fever started at the age of 1 year and was of gradual onset, low grade with no specific periodicity. Eight other episodes had the same nature as the first one. There was no history of convulsions, loss of consciousness or problems with micturition. At the time of referral it was the third admission due to the above complaints. The child also had delayed milestones and his diet was inadequate in quality and quantity.

He was the last born in a family of 4 children, the rest of whom were doing fine. The gap between him and the third born was 12 years. His mother was 43 years and father was 45 years old.

On examination he was alert, febrile $\left(38.5^{\circ} \mathrm{C}\right)$, acyanotic, and had up-slanting eyes, low set ears, flat nasal bridge, small chin, short neck, pigeon chest, short palm with single crease and 
webbedtoes.

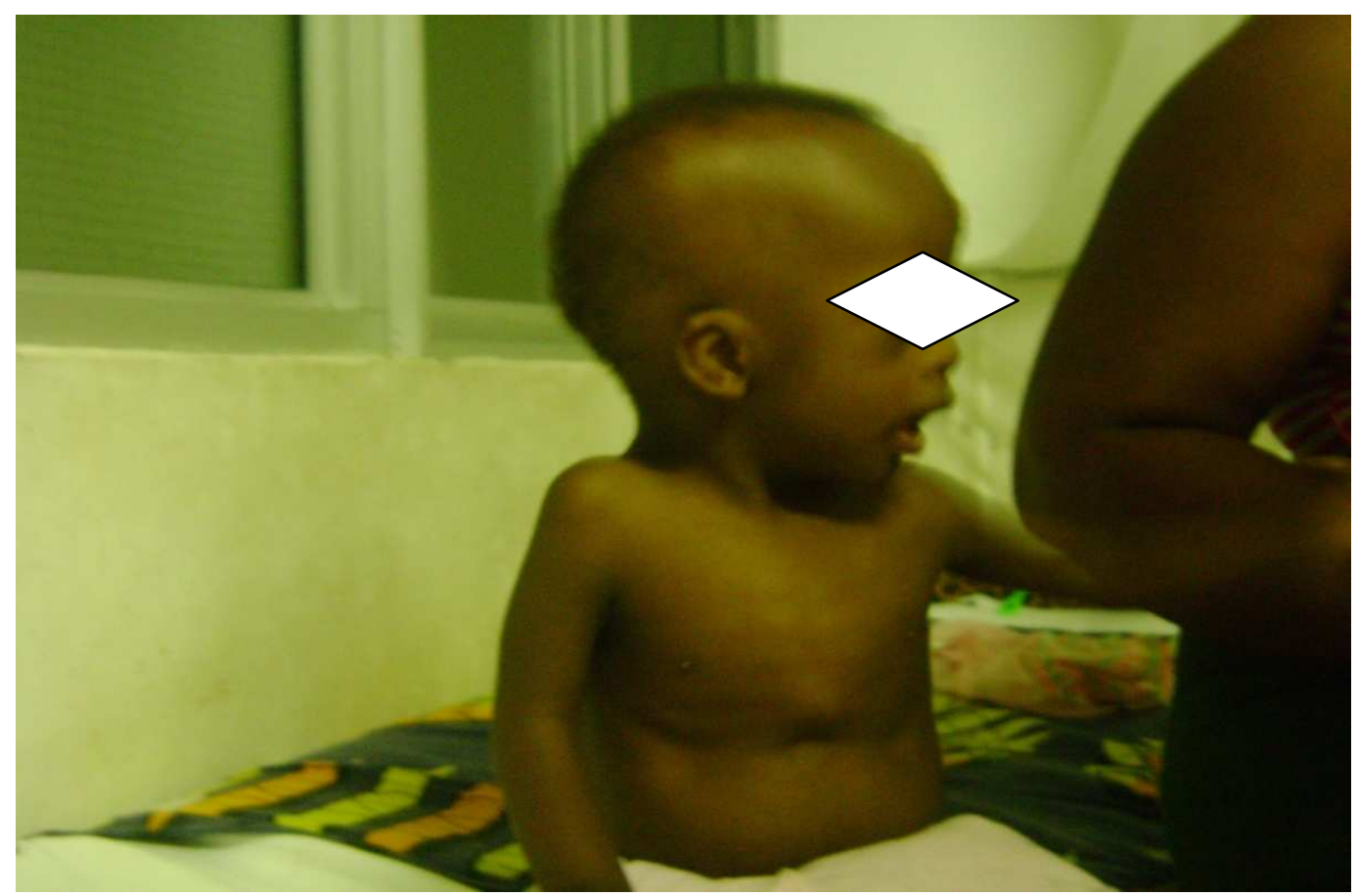

KM has up-slanting eyes, low set ears, small chin, flat nasal bridge and short webbed neck. (photo by Elisha Osati: Trisomy 21).

He was stunted and severely malnourished. Respiration rate was 62 breaths/minute and pulse rate 121 beats/ $\min$. The apex beat was felt at the $4^{\text {th }}$ intercostal space in the left mid-clavicular line. The first and second heart sounds were heard and a pan-systolic murmur was auscultated at the lower left sternal edge. The child had impaired speech, reduced muscle bulk and muscle tone, and 
muscle power of grade 3 with normal superficial and deep tendon reflexes.

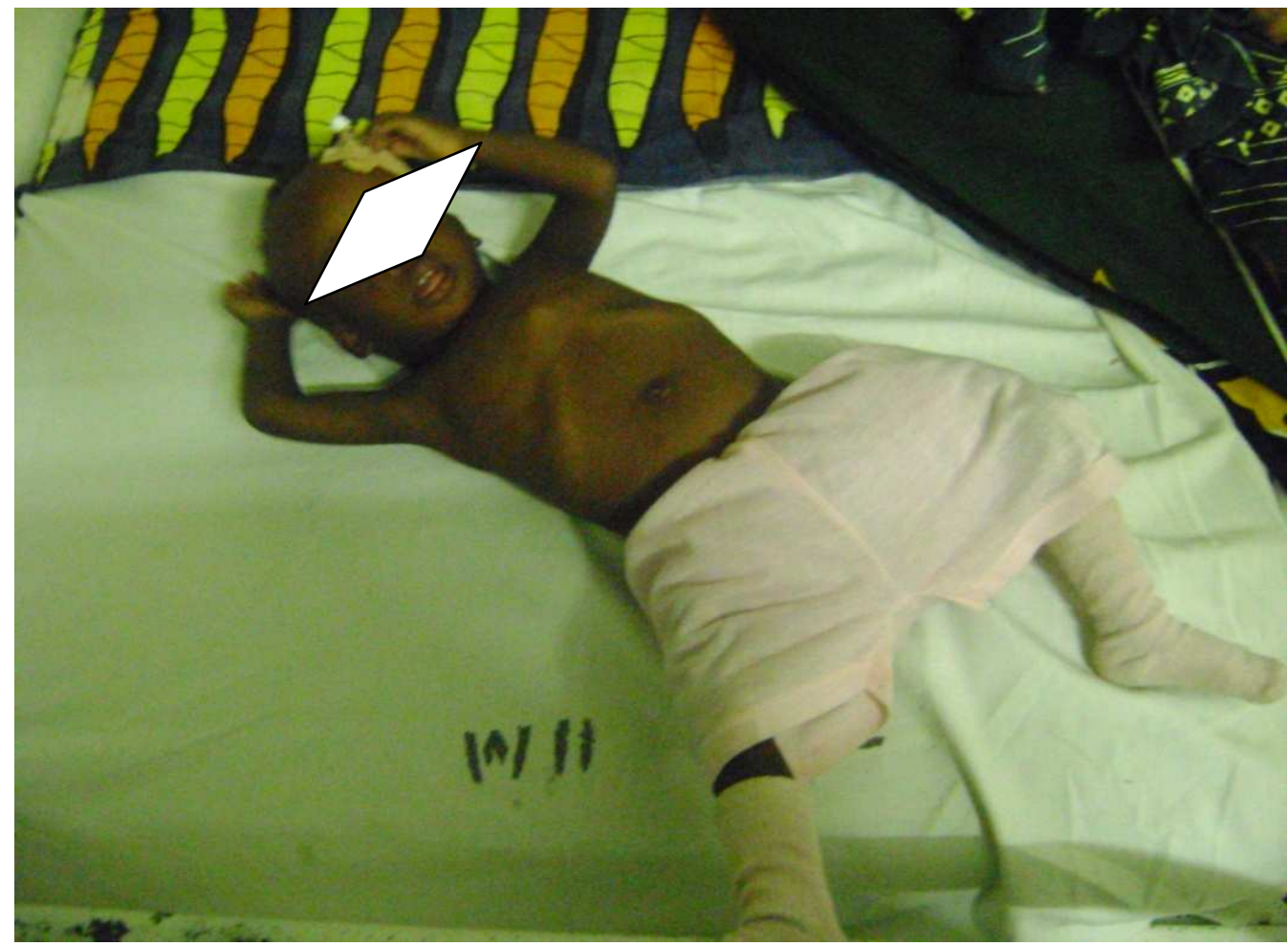

KM had reduced muscle bulk, a protruded tongue and pigeon chest (photo by Elisha Osati: Trisomy 21)

Chest X-ray revealed cardiomegaly, ECG revealed large VSD $15 \mathrm{~mm}$, small PDA and mild LV dilatation. Blood culture and sensitivity isolated Klebsiella pneumoniae and Staphylococcus aureus.

He was kept on digoxin $0.06 \mathrm{mg}$ orally $\mathrm{OD}$ for $1 / 12$, aldactone $6.25 \mathrm{mg}$ orally OD for $1 / 12$, Frusemide $10 \mathrm{mg}$ orally OD for 1/12, Ceftriaxone $750 \mathrm{mg}$ orally OD for 10/7, Paracetamol $125 \mathrm{mg}$ orally whenever temperature rose above $38.5^{\circ} \mathrm{C}$, Multivitamin $2.5 \mathrm{ml}$ orally OD for 1/12, Starter F-75 and then Catch-up F-100. He was then referred to Regency Hospital in India for open heart surgery which was successfully performed. 


\section{DISCUSSION}

This is a classical case of Down syndrome with the history and physical features similar to those reported in literature. The child diagnosed with Down syndrome following observation of dysmorphic features, cheerfulness, congenital heart disease (VSD), developmental delay, reduced muscle tone and late bearing (43 years old maternal and 45 years old of paternal age).

The proper management of associated illhealth and care of a child with Down syndrome may lead to better chances of survival and less morbidity.

This disease syndrome can be reduced in the community by avoiding bearing children at advanced age. However, most babies with Down syndrome (more than 85 percent) are born to mothers younger than 35 years $^{6}$. Continued counseling of the parents on the condition of the child and provision of special education and occupational training that aim at helping the child develop their full potential are important. Recent dramatic improvements in medical care of associated infections and cardiac conditions lead to improved quality of life and increased life expectancy of children with Down Syndrome.

\section{REFERENCES}

1. William W.H. Genetics \& Dysmorphology. Current pediatrics Diagnosis and Treatment $18^{\text {th }}$ Edition Chapter 33.

2. Behrman R. E, et al. Chromosomal Clinical Abnormalities. Nelson textbook of pediatrics $17^{\text {th }}$ Edition chapter 70 .

3. Holiday. J, Collins. V, Riley. M, et al. Has prenatal screening influenced the prevalence of commorbities associated with Down syndrome and subsequent survival? Pediatrics, 2009; 123(1): 256-261.

4. Jaruratanasirikul. S, Soponthammarak. S, Chanvitan. P, et al. Clinical abnormalities, intervention program and school attendance of Down's syndrome children in Southern Thailand. Journal of the Medical Association of Thailand, 2004; 87(10): 1199-204.

5. Newberger. D, Down Syndrome: Prenatal Risk Assessment and Diagnosis, The American Academy of family physician, 2000; 20 (8). 